\title{
CONTENIDO DE LOS NUTRIENTES BÁSICOS EN CATOLACCUS GRANDIS BURKS CRIADOS SOBRE LARVAS DEL PICUDO DEL ALGODON1
}

\author{
LÚCIA HELENA AVELINO ARAUJO², ANTONIO ALVAREZ GUERRA ${ }^{3} y$ ENRIQUE ARANDA HERRERA ${ }^{4}$
}

\begin{abstract}
RESUMEN - El objetivo del trabajo fue determinar los niveles de carbohidratos, proteínas solubles y aminoácidos libres de larvas, pupas hembras y adultos hembras de Catolaccus grandis (Burks) (Hymenoptera: Pteromalidae) criados sobre larvas del picudo del algodón envenenadas por hembras del parasitoide y por larvas de primer instar del parasitoide. Esto estudio fue conducido en la Unidade de Investigación de Control Biologico de Plagas del Departamento de Agricultura de los Estados Unidos de la América, en Weslaco, Texas. Las 20 muestras de cada uno de los tres estados de desarrollo: tercer instar larval, pupas hembra y adultos hembra del parasitoide $C$. grandis, fueron separadas y pesadas individualmente y se cuantió el contenido de carbohidratos totales, proteínas solubles totales y aminoácidos libres criados en diferentes sustratos. Los resultados obtenidos confirman la existencia de patrones metabólicos significativamente distintos de estos nutrientes básicos.
\end{abstract}

Términos para índice: Gossypium hirsutum, Anthonomus grandis, parasitoides, hemolinfa, carbohidratos, proteínas, aminoácidos, venenos.

\section{BASIC NUTRIENTS CONTENT OF CATOLACCUS GRANDIS BURKS REARED IN COTTON BOLL WEEVIL LARVAE}

\begin{abstract}
The aim of this work was to determine the levels of carbohydrate, soluble proteins and free amino acids of larvae, pupae and adult females Catolaccus grandis Burks (Hymenoptera: Pteromalidae) which were reared in cotton (Gossypium hirsutum L. r. latifolium Hutch) boll weevil (Anthonomus grandis) larvae venomized by ectoparasitoid of female and $1^{\text {st }}$ instar ectoparasitoid larvae. This study was carried out at the Biological Control of Pests Research Unit, Weslaco, Texas. The twenty samples of each one of three stages of development: $3^{\text {rd }}$ instar larval, female pupae and female adult of parasitoid $C$. grandis were separated and individually weighted, and levels of carbohydrates, proteins and amino acids were quantified when reared in different substrates. The results confirmed the existence of metabolic patterns significantly distinct from the basic nutrient model.
\end{abstract}

Index terms: Gossypium hirsutum, Anthonomus grandis, parasitoids, haemolymph, carbohydrates, proteins, amino acids, venoms.

\footnotetext{
${ }^{1}$ Aceptado para publicación en 24 de enero de 2000.

Parte de la tesis de maestria del primer autor, Instituto Tecnologico y de Estudios Superiores (ITESM), Monterrey, México.

${ }^{2}$ Ing. Agr., M.Sc., Embrapa-Centro Nacional de Pesquisa de Algodão (CNPA), Caixa Postal 174, CEP 58107-720 Campina Grande, PB, Brasil. E-mail: lucia@cnpa.embrapa.br

${ }^{3}$ Ing. Agr., Ph.D., Biological Control of Pests Research Unit, USDA-ARS, 2413 E. HWY 83, Weslaco, Texas, USA, 7859.

${ }^{4}$ Ing., Agr., Ph.D., Programa de Graduados en Agricultura, ITESM, Sucursal de correos "J", CP 64849 Monterrey, N.L., México. E-mail: earanda@campus.mty.itesm.mx
}

\section{INTRODUCCIÓN}

El control natural del picudo del algodonero, Anthonomus grandis Boheman es realizado tanto por la acción de factores climáticos como biológicos principalmente por insectos parásitos y ácaros. Estos artrópodos se alimentan interna o externamente de las fases inmaduras del picudo. De las 42 especies de artrópodos que se sabe parasitan al picudo, 33 pertenecen al orden Hymenoptera, seis a Diptera, una a Coleoptera y dos pertenecen a Acarina (Cross $\&$ Chesnut, 1971). 
La información existente sobre los parásitos de A. grandis ha sido obtenida en su gran mayoría de trabajos de investigación hechos en los Estados Unidos de América. Los primeros estudios fueron hechos por Townsend (1895), Rangel (1901), Ashmead (1902) y Pierce (1908). Estudios posteriores hechos por Chesnut \& Cross (1971), muestran la importancia de estes insectos como agentes de control del picudo en este país durante un periodo de treinta años.

Catolaccus grandis fue descrito por vez primera por Burks (1954) en Nicaragua, como un parasitoide primario del picudo del algodonero. Los seguientes registros como parásito del picudo fueron hechos en Sonora, México entre 1960 y 1961 y en Nicaragua en 1961 (Cross \& Mitchell,1969). Los estudios hechos por los mismos Cross y Mitchell respecto a la distribución de C. grandis lo sitúan, como ya se mencionó, como el parásito mas importante del picudo en la costa del Pacífico en México y Centro América y lo señalan como un agente potencial para el control biológico del picudo.

Apesar de su aparente inhabilidad para establecerse en regiones subtropicales y templadas de los Estados Unidos de América el parásito exhibe varias características que sugieren un potencial de eficiencia para programas de control biológico, como por ejemplo su alta tasa de incremento (Johnson et al., 1973; Morales-Ramos \& Cate, 1992a). Los atributos biológicos de $C$. grandis que lo hacen un excelente candidato para suprimir poblaciones de picudo incluyen: una fecundidad más alta que del picudo del algodón, la cual le habilita para dar una respuesta numérica efectiva (Morales-Ramos \& Cate, 1992b); capacidad para hallar el hospedero en condiciones de baja densidad (Morales-Ramos, 1991); sincronización con el ciclo de vida del hospedero bajo una diversidad de regímenes de temperatura (MoralesRamos \& Cate, 1993); especificidad sobre el hospedero (Burks, 1954) y búsqueda del parasitoide por el huésped en campo en estadios susceptibles (tercer instar y pupa) (Summy et al., 1992).

Antes de la oviposición las hembras de muchos parasitoides como C. grandis paralizan a sus víctimas por inyección de un veneno via el ovipositor para prevenir su movimiento y no dañar los huevos que pueden ser depositados en la superficie del integumento de la misma (Adams et al., 1969). Las larvas de un insecto envenenado, por ejemplo, del picudo del algodonero parasitados por C. grandis, pueden sostener el completo desarrollo larval del hospedero y de ello mismo (Guerra et al., 1993b).

El modo de acción de los venenos y la importancia de ellos en la regulación del metabolismo del hospedero para el desarrollo del parasitoide pueden ofrecer nuevos conocimientos dentro de la relación parásito-hospedero. Hay muchas evidencias que sugieren que la especificidad del hospedero puede depender del efecto de un veneno en el mismo y que los cambios inducidos por el veneno pueden ser necesarios para el desarrollo del parasitoide (Price, 1975; Guerra et al., 1993a, 1994).

Atualmente en los Estados Unidos de América los adultos del $C$. grandis están siendo criados utilizando el sistema convencional in vivo con larvas de tercer instar del hospedero natural A. grandis recluídas en celdas de Parafilm (Cate, 1987; MoralesRamos \& Cate, 1992b; Roberson \& Harsh, 1993).

El objetivo de este trabajo fue determinar los niveles de carbohidratos totales, proteínas solubles totales y aminoácidos libres de $C$. grandis cuando desarrollados sobre larvas de picudo envenenadas por larvas de primer ínstar y adultos hembra del parasitoide.

\section{MATERIAL Y MÉTODOS}

Utilizando la técnica de cría descrita por Cate (1987), las poblaciones experimentales del parasitoide $C$. grandis fueron mantenidas in vivo en larvas de tercer instar de A. grandis, en el insectario del Laboratorio de Control Biológico del Departamento de Agricultura de los Estados Unidos de América (USDA) en Weslaco, Texas, en 1995.

Durante el desarrollo de la investigación se emplearon larvas de tercer instar de $A$. grandis para nutrir a los estadios inmaduros del parasitoide por lo que, para facilitar la descripción de los mismos se utilizarán las siguientes abreviaturas: larvas EHP, para indicar que los parasitoides fueron alimentados in vivo sobre larvas de picudo envenenadas por hembras del mismo parasitoide; larvas ELP: para indicar que los parasitoides fueron alimentados in vivo sobre larvas de picudo envenenadas por efecto de la alimentación inicial de las mismas larvas del parasitoide, las cuales fueron depositadas directamente sobre el integumento de las larvas del hospedero. 


\section{Bioensayo con larvas EHP}

Larvas de tercer instar de A. grandis desarrolladas en dieta artificial fueron colocadas individualmente en celdillas de Parafilm (Cate, 1987) para criar C. grandis in vivo. Estas celdillas fueron expuestas a hembras del parasitoide para que éstas envenenaran al hospedero y depositaran sus huevecillos cerca o sobre este último.

\section{Bioensayo con larvas ELP}

Para investigar si larvas no envenenadas por hembras adultas de $C$. grandis pueden servir como un medio nutricional adecuado para propagar el parasitoide, larvas individuales de picudo del algodonero no envenenadas fueron puestas en las celdillas de Parafilm ya mencionadas. Hecho ésto, por medio de un pincel fino se transfería una larva recién eclosionada procedente de la colonia del laboratorio, sobre la larva de $A$. grandis para que en este caso fuera la misma larva del parasitoide la que envenenara al hospedero, tal como lo reporta Guerra et al. (1993a).

\section{Preparación de las muestras}

En este estudio, 20 individuos de cada uno de tres estados de desarrollo: tercer instar larval, pupas hembra y adultos hembra del parasitoide $C$. grandis fueron pesados individualmente. Larvas de tercer instar de $C$. grandis fueron colectadas sobre larvas del picudo tres días despúes de la infestación; las pupas hembra fueron separadas de los machos (Johnson et al., 1973) a los seis días aproximadamente y los adultos dentro de las primeras 24 horas de haber emergido. A continuación se homogenizaron las muestras en forma individual en $2 \mathrm{~mL}$ de una solución salina $(0,85 \% \mathrm{NaCl})$, a una velocidad de $9.500 \mathrm{rpm}$ durante 30 segundos. Los homogenatos fueron centrifugados para separar todas las partículas insolubles, durante 5 minutos. A continuación el sobrenadante fué removido con una pipeta y trasvasado en microtubos desechables de $2 \mathrm{~mL}$ que fueron posteriormente guardados a $-20^{\circ} \mathrm{C}$ hasta su utilización en el análisis de carbohidratos, proteínas y aminoácidos libres.

Análisis de carbohidratos totales, proteínas solubles totales y aminoácidos libres

El contenido total de carbohidratos fue determinado colorimétricamente de acuerdo con el procedimiento de Dubois et al. (1956), utilizando alícuotas de $0,5 \mathrm{~mL}$ del homogenato de cada muestra (individuo). Para preparar la curva estándard se utilizó glucosa. El contenido de proteínas solubles totales fue determinado usando el método del tinte azul-brilhante descrito por Bradford (1976) utilizan- do alícuotas de $0,1 \mathrm{~mL}$ del homogenato original. La curva estándard se preparó con una serie de diluciones de la proteína estándard (albúmina de suero de bovino) y agua desionizada (Millipore). El método que se utilizó para analizar los aminoácidos libres es el descrito por Rosen (1957) con algunas modificaciones, utilizándose alícuotas de $0,5 \mathrm{~mL}$ del homogenato original. El aminoácido leucina fue utilizado para la construcción de la curva estándard.

\section{Cálculo de los niveles de componentes básicos}

Con el objeto de transformar los valores de absorbancia de las muestras, en los correspondientes valores de contenido de carbohidratos, proteínas totales y aminoacidos libres en el insecto vivo de acuerdo con las curvas estándard construídas en cada análisis, se utilizó la siguiente ecuación matemática:

$\mathrm{E}=(\mathrm{A} / \mathrm{B}) \times(\mathrm{C} / \mathrm{D})$

E: concentración final de carbohidratos, proteínas y aminoácidos en $\mu$ moles $/ \mathrm{mg}$ peso fresco del insecto;

A: concentración en la muestra ( $\mu$ moles/peso fresco);

B: volúmen de la alícuota $(\mathrm{mL})$;

C: volúmen total de la muestra $(\mathrm{mL})$;

D: peso fresco del insecto (mg).

\section{Análisis estadístico}

Todos los datos fueron analizados usando un programa de modelo lineal general en PC-SAS (SAS Institute, 1990) y los promedios se calcularon utilizando la prueba de rangos múltiples de Waller-Duncan $(\mathrm{P}=0,05)$.

\section{RESULTADOS Y DISCUSIÓN}

La incipiente literatura que se ha publicado sobre el tema del efecto del veneno de los parasitoides sobre la modificación del contenido de nutrientes básicos en la hemolinfa de sus hospederos, enfatiza exclusivamente la variación en proteínas solubles y los aminoácidos libres de estos últimos (Ferkovich et al., 1983; Lee et al., 1990; Guerra et al., 1993a). Los resultados de la presente investigación constituyen el primer reporte de la variación del contenido total de tres nutrientes básicos: carbohidratos, proteínas y aminoácidos, en larvas, pupas y adultos hembra del parasitoide $C$. grandis, criados en diferentes sustratos vivos.

A continuación se consignan y discuten los datos cuantitativos obtenidos del análisis químico del contenido total de carbohidratos, proteínas solubles 
y aminoácidos libres en la hemolinfa de larvas, pupas y adultos hembra de $C$. grandis, producidos en sustrato vivo (larvas de $A$. grandis envenenadas e no envenenadas por las hembras del parasitoide).

En las pruebas analíticas hechas con larvas de tercer instar no se detectó diferencia estadística significativa en la concentración de carbohidratos entre las larvas EHP y las ELP (Cuadro 1). La concentración similar de carbohidratos en las muestras de larvas del parasitoide alimentadas in vivo (larvas EHP y ELP), sugiere que el efecto del doble envenenamiento (el ocasionado inicialmente por la hembra grávida y por la larva de primer instar después) propuesto en este trabajo, no tiene aparentemente mayor efecto que el envenenamiento sencillo ocasionado por la larva de $C$. grandis de primer instar (larvas ELP).

El análisis estadístico de la información indica que no hay diferencia significativa entre las pupas de los parasitoides criados sobre larvas EHP y aquellas criadas sobre larvas ELP (Cuadro 1). En el estado de pupa el animal atraviesa por una histólisis general

CUADRO 1. Concentraciones promedio ( $\mu$ moles $/ \mathrm{mg}$ peso vivo del insecto) y error estandard de carbohidratos, proteínas solubles totales y de aminoácidos libres en homogenatos de larvas de tercer instar, pupas hembra y adultos hembra de Catolaccus grandis Burks desarrollados en dos sustratos nutritivos, promedios de 20 repeticiones ${ }^{1}$.

\begin{tabular}{|c|c|c|c|}
\hline Sustrato $^{2}$ & Larva & Pupa & Adulto \\
\hline & \multicolumn{3}{|c|}{ Carbohidratos } \\
\hline EHP & $31,43 \pm 1,37 \mathrm{a}$ & $29,16 \pm 1,69 b$ & $144,54 \pm 10,65 a$ \\
\hline \multirow[t]{2}{*}{ ELP } & $33,20 \pm 0,92 \mathrm{a}$ & $27,22 \pm 1,53 b$ & $81,44 \pm 12,10 b$ \\
\hline & \multicolumn{3}{|c|}{ Proteínas solubles totales } \\
\hline EHP & $60,89 \pm 2,20 \mathrm{a}$ & $47,32 \pm 1,63 b$ & $104,88 \pm 2,44 \mathrm{a}$ \\
\hline \multirow[t]{2}{*}{ ELP } & $49,02 \pm 1,69 b$ & $80,21 \pm 3,02 \mathrm{a}$ & $45,70 \pm 3,23 b$ \\
\hline & \multicolumn{3}{|c|}{ Aminoácidos libres } \\
\hline EHP & $17,70 \pm 1,95 b$ & $10,92 \pm 0,90 \mathrm{~b}$ & $38,75 \pm 4,51 \mathrm{a}$ \\
\hline ELP & $42,36 \pm 2,73 \mathrm{a}$ & $26,33 \pm 1,30 \mathrm{a}$ & $18,05 \pm 1,11 b$ \\
\hline \multicolumn{4}{|c|}{$\begin{array}{l}{ }^{1} \text { Las medias en cada columna seguidas por la misma letra no difieren sig- } \\
\text { nificativamente }(\mathrm{P}<0,05) \text {, según pruebas de rangos múltiples de Waller- } \\
\text { Duncan (SAS Institute, 1990). } \\
{ }^{2} \text { EHP: larvas de A. grandis envenenadas por la hembra de C. grandis; } \\
\text { ELP: larvas de A. grandis envenenadas por larva de primer instar de } \\
\text { C. grandis. }\end{array}$} \\
\hline
\end{tabular}

Pesq. agropec. bras., Brasília, v.35, n.9, p.1701-1707, set. 2000 que hace imposible separar los efectos de una regulación metabólica de la hemolinfa. En esta fase muchos otros tejidos estructurales del insecto en metamorfosis enmascaran toda cuantificación de los nutrientes básicos que se intente realizar.

En el caso del adulto hembra se evidencía una diferencia significativa entre los niveles de carbohidratos en los dos sustratos experimentales. En parasitoides alimentados en larvas EHP se observó una mayor concentración de carbohidratos. En larvas EHP la concentración es casi dos veces la de los adultos de larvas ELP (Cuadro 1). Cuando se compara la proporción del contenido de carbohidratos de larvas y adultos dentro de un mismo sustrato alimentício, resulta que la proporción normal (insectos EHP) es de 1:4,6 y la de los insectos ELP es de 1:2,4, lo que evidencía una clara alteración del metabolismo de estos nutrientes básicos a través del desarrollo fisiológico de los parasitoides criados en los distintos sustratos.

Los niveles de proteína soluble variaron significativamente dependiendo del sustrato nutritivo usado y del estado de desarrollo del parasitoide (Cuadro 1). Durante este trabajo se encontraron diferencias significativas en los niveles de proteínas solubles, tanto entre los dos sustratos de crecimiento empleados cuando se considera un estado fisiológico de desarrollo dado, como cuando se comparan entre sí los distintos estados de desarrollo en un sustrato dado. Los niveles mas altos de proteína soluble se encontraron en larvas de tercer instar de C. grandis que se desarrollaron parasitando larvas EHP (larvas de A. grandis envenenadas por hembras del parasitoide). Las concentraciones de proteínas solubles que se encontraron en estos dos tratamientos fueron estadísticamente diferentes $(\mathrm{P}<0,05)$. En las pruebas analíticas hechas con pupas se detectó diferencia estadística significativa entre el nivel de proteína soluble de parasitoides en ELP y en EHP. Esto último evidenció cerca de un $40 \%$ de reducción en el contenido de proteína soluble con respecto al promedio de las pupas ELP.

Los resultados de los análisis realizados para detectar la concentración de proteína soluble total en parasitoides adultos indican que, estadísticamente, existe diferencia significativa $(\mathrm{P}<0,05)$ entre los dos sustratos (Cuadro 1). Los niveles mas altos de pro- 
teínas solubles se detectaron en parasitoides que se desarrollaron en larvas EHP. El nivel de la primera (EHP) es ligeramente más del doble de la segunda (ELP); ésto refleja el efecto de los dos envenenamientos sucesivos sobre el hospedero, que se manifiesta en una mayor producción de aminoácidos que son convertidos a proteínas solubles de reserva. En el caso de hospederos envenenados solamente por larvas de primer instar de C. grandis (ELP), cabe solo esperar un solo pico de producción de aminoácidos y, por lo tanto, sola una conversión importante de éstos en proteínas de reserva.

En esta investigación se pretende introducir por primera vez el concepto de doble envenenamiento que existe normalmente en la naturaleza y que no ha sido reportado como un evento normal en la reproducción de parasitoides.

Los resultados del análisis químico de aminoácidos libres variaron significativamente dependiendo de la dieta utilizada y del estado de desarrollo de C. grandis (Cuadro 1). El análisis estadístico aplicado a los datos de concentración de aminoácidos libres detectados en larvas de $C$. grandis alimentadas en los dos sustratos nutritivos, indican que hay diferencia significativa entre los parasitoides alimentados con larvas ELP y EHP. La concentración de aminoácidos libres en larvas EHP fue 2,3 veces menor que la concentración del promedio de las larvas ELP. Una posible explicación de estos resultados puede ser la siguiente: como en la prueba donde se criaron parasitoides sobre larvas EHP se utilizaron larvas del hospedero de tercer instar, es posible que el análisis de los aminoácidos fuera hecho una hora o dos después del envenenamiento inicial. En este caso ya es sabido que los niveles de aminoácidos libres desminuyen significativamente y estos aminoácidos son convertidos luego a proteínas. Podrá suponerse, por otra parte, que los análisis hechos con larvas hospederas parasitadas sólo por las larvas recién eclosionadas del parasitoide (ELP), fueron hechas antes del tiempo que los niveles de aminoácidos inducidos por el parasitoide se encuentran aún muy altos.

Para pupa hembra los datos indicaron una diferencia significativa $(\mathrm{P}<0,05)$ en las concentraciones de aminoácidos libres detectados respecto a los dos sustratos nutritivos. El nivel más bajo de aminoácidos se encontró en los parasitoides que se desarrollaron en larvas EHP. Este nivel es 2,4 veces menor que encontrado en las pupas ELP. En este caso los resultados obtenidos con pupas de $C$. grandis reflejan directamente los cambios metabólicos que se llevan a cabo en las larvas. Sin embargo, como se ha discutido en este estudio, debe tomarse en cuenta lo complejo que resulta formular razones para explicar perfiles metabólicos de nutrientes básicos, en un medio tan heterogéneo como lo es el proceso de autólisis a nivel molecular que ocurre durante la metamorfosis.

En el caso adulto hembra el análisis estadístico en este caso indica que hubo diferencia significativa entre los parasitoides alimentados con larvas EHP y ELP. El nivel de concentración de aminoácidos en los adultos procedentes de larvas EHP es el doble de lo segundo (ELP). Los aminoácidos libres en los adultos EHP es 2,2 veces mayor que el promedio de aminoácidos de los adultos ELP. Estos resultados son de gran interés puesto que las concentraciones de aminoácidos encontrados en larvas y pupas de C. grandis alimentadas con larvas EHP, fueron significativamente menores que aquellas encontradas en los mismos estadios de desarrollo criados con larvas ELP.

La primer evidencia del efecto regulador del veneno de las hembras adultas de $C$. grandis sobre el metabolismo de aminoácidos libres y proteína soluble de la hemolinfa de larvas de A. grandis, la han proporcionado Guerra et al. (1993a). Estos investigadores reportan un incremento bien perceptible en la concentración de aminoácidos a los pocos minutos del ataque de la hembra sobre el hospedero, seguido de un descenso considerable y constante de la misma durante las siguientes 24 horas. Después de este lapso la concentración aumenta ligeramente - pero por debajo de la concentración alcanzada en el primer pico - hasta las 72 horas, para disminuir nuevamente en las siguientes 46 horas. Por otra parte, la concentración de proteína soluble sigue el mismo patrón de incremento brusco de los aminoácidos en la primera hora después del ataque, para que, a partir de la segunda hora, se presente un marcado incremento en la concentración que perdura durante las siguientes 46 horas. Esta tendencia de la concentración de las proteínas a subir y la de los aminoácidos 
a bajar se mantuvo durante las siguientes 72 horas, evidenciando un mecanismo recíproco de regulación cuyo posible significado biológico también discuten estos investigadores. Muy significativo también es el hecho de que el patrón de variación contrastante postenvenenamiento de los aminoácidos libres y la proteína soluble, que ocurre a través del tiempo en la hemolinfa del hospedero, también se repitió en la hemolinfa de las larvas de $C$. grandis.

Aún cuando en la presente investigación no se realizó un análisis químico postenvenenamiento a diferentes tiempos, es posible detectar claramente diferencias en la tendencia de la variación de aminoácidos y proteínas cuando se comparan los distintos sustratos alimenticios. En los insectos EHP los aminoácidos se incrementan 2,2 veces en el adulto con respecto a la larva; en tanto que con las proteínas pasa lo mismo en una magnitud de 1,7 veces. Dado que se trata de adultos hembra, era de esperarse un incremento de ambos nutrientes para cubrir las necesidades mayores de construcción de tejido (sobre todo muscular) y para el proceso de vitelogénesis de esta fase de desarrollo.

Los resultados obtenidos confirman la existencia de patrones metabólicos significativamente distintos de estos nutrientes básicos. Finalmente, se confirma el hallazgo de otros investigadores del papel regulador del metabolismo de nutrientes básicos en la hemolinfa del hospedero por acción del veneno de $C$. grandis y, además la acción del doble envenenamiento de $C$. grandis (primero por la hembra que paraliza inicialmente al hospedero y después por la larva de primer instar de $C$. grandis al alimentarse del hospedero).

\section{CONCLUSIONES}

1. El parasitoide C. grandis presenta niveles significativamente distintos de los nutrientes básicos (carbohidratos, proteínas solubles y aminoácidos libres) en todos los estadios (larva, pupa y adulto).

2. Se confirma el papel regulador del metabolismo de nutrientes básicos en la hemolinfa del hospedero por acción del veneno de $C$. grandis y, además de la acción del doble envenenamiento de $C$. grandis.

\section{AGRADECIMIENTOS}

Al Departamento de Agricultura (USDA - ARS), Weslaco, Texas, USA, en la persona del Dr. Edgar King; a la M.Sc. Hilda Sonia por su valiosa colaboración.

\section{REFERENCIAS}

ADAMS, C.H.; CROSS, W.H.; MITCHELL, H.C. Biology of Bracon mellitor: a parasite of the boll weevil. Journal of Economic Entomology, Lanham, v.62, n.4, p.889-896, 1969.

ASHMEAD, W.H. A new Bruchophagus from Mexico. Bolletin Comercial Parasitologico, Washington, v.1, p.404,1902.

BRADFORD, M.M. A rapid and sensitive method for the quantization of microgram quantities of protein utilizing the principle of protein-dye binding. Annals of Biochemistry, Lexington, v.72, p.248-254, 1976.

BURKS, B.D. Parasitic wasps of the Catolaccus group in the Americas. USDA Technology Bulletin, Washington, v.1093, p.1-21, 1954.

CATE, J.R. A method of rearing parasitoids of boll weevil without the host plant. Southwestern Entomologist, Dallas, v.12, p.211-215, 1987.

CHESNUT, T.L.; CROSS, W.H. Arthropod parasites of boll weevil, Anthonomus grandis Boheman. 2. Comparisons of their importance in the United States over a period of thirty eight years. Entomological Society of America Annals, Lanham, v.64, p.549-557, 1971.

CROSS, W.H.; CHESNUT, T.L. Arthropod parasites of the boll weevil, Anthonomus grandis. 1. An annotated list. Entomological Society of America Annals, Lanham, v.64, p.516-527, 1971.

CROSS, W.H.; MITCHELL, H.C. Distribution and importance of Heterolaccus grandis as a parasite of the boll weevil. Entomological Society of America Annals, Lanham, v.62, p.235-236, 1969.

DUBOIS, M.; GILLES, K.A.; HAMILTON, J.K.; ROBERS, P.A.; SMITH, F. Colorimetric method for determination of sugars and related substances. Analytical Chemistry, Washington, v.28, p.350356, 1956. 
FERKOVICH, S.M.; GREANY, P.D.; DILLARD, C. Changes in haemolymph proteins of the fall army worm, Spodoptera frugiperda (J.E. Smith) associated with parasitism with the braconid parasitoid Cotesia marginiventris (Cresson). Journal of Insect Physiology, Oxford, v.29, p.933-942, 1983.

GUERRA, A.A.; MARTÍNEZ, S.; RIO, H.S. del. Natural and synthetic oviposition stimulants for Catolaccus grandis (Burks) females. Journal of Chemical Entomology, Weslaco, v.20, p.1583-1594, 1994.

GUERRA, A.A.; ROBACKER, K.M.; MARTÍNEZ, S. Free amino acid and protein titers in Anthonomus grandis venomized by Bracon mellitor. Entomophaga, Paris, v.38, p.519-525, 1993a.

GUERRA, A.A.; ROBACKER, K.M.; MARTÍNEZ, S. In vitro rearing of Bracon mellitor and Catolaccus grandis with artificial diets devoid of insects components. Entomologia Experimentalis et Applicata, Dordrecht, v.68, p.303-307, 1993b.

JOHNSON, W.L.; CROSS, W.H.; McGOVERN, W.I.; MITCHELL, H.C. Biology of Heterolaccus grandis in laboratory culture and its potential as an introduced parasite of the boll weevil in the United States. Environmental Entomology, Lanham, v.2, p.112118, 1973.

LEE, H.P.; KO, T.Y.; LEE, K.R. Changes in haemolymph metabolites of Lymantria dispar L. parasitized by the pupal parasitoid Brachymeria lasus Walker Kor. Journal of Entomology, Oxford, v.20, p.23-31, 1990.

MORALES-RAMOS, J.A. Rate of increase, functional response, and development of Catoloccus grandis (Bruks) (Hymenoptera: Pteromalidae). Austin : Texas A \& M University, 1991. 126p. Ph.D. Thesis.

MORALES-RAMOS, J.A.; CATE, J.R. Laboratory determination of age-dependent fecundity development, and rate of increase of Catolaccus grandis (Burks) (Hymenoptera, Pteromalidae). Entomological Society of America Annals, Lanham, v.85, p.469-476, 1992a.

MORALES-RAMOS, J.A.; CATE, J.R. Rate of increase and adult longevity of Catolaccus grandis (Burks)
(Hymenoptera: Pteromalidae) in laboratory at four temperatures. Environmental of Entomology, Lanham, v.21, p.620-627, 1992b.

MORALES-RAMOS, J.A.; CATE, J.R. Temperaturedependent developmental rates of Catolaccus grandis (Burks) (Hymenoptera: Pteromalidae). Environmental of Entomology, Lanham, v.22, p.226-233, 1993.

PIERCE, W.D. Studies of parasites of the cotton boll weevil. USDA Bulletin, Washington, v.73, p.631636, 1908.

PRICE, P.W. Reproductive strategies of parasitoids. In: PRICE, P.W. (Ed.). Evolutionary strategies of parasitic insects and mites. New York : Plenum, 1975. p.87-111.

RANGEL, A.F. Tercer informe acerca del picudo del algodón Anthonomus grandis. Boletin Comercial Parasitologico, Tamaulipas, v.1, p.197-206,1901.

ROBERSON, J.L.; HARSH, D.K. Mechanized production processes to encapsulate boll weevil larvae Anthonomus grandis for mass production of Catolaccus grandis (Burks). In: BELTWIDE COTTON CONFERENCE, 1993, Memphis. Proceedings. Memphis : National Cotton Council of America, 1993. v.2, p.922-923.

ROSEN, H.A. Modified ninhydrin colorimetric analysis for amino acids. Archives of Biochemistry and Biophysics, San Diego, v.67, p.10-15,1957.

SAS INSTITUTE (Cary, Estados Unidos). SAS/STAT guide for personal computers: version 6 . Cary, 1990. 1042p.

SUMMY, K.R.; MORALES-RAMOS, J.A.; KING, E.G. Ecology and potential impact of Catolaccus grandis (Burks) on boll weevil infestations in the Lower Rio Grande Valley. Southwestern Entomologist, Dallas, v.17, p.279-288, 1992.

TOWNSEND, C.H.T. Reports on the Mexican cotton boll weevil in Texas Anthonomus grandis Boheman. Insect Life, Washington, v.2, p.348-350,1895. 